\title{
Stage actors and emotions at work
}

\section{Stina Bergman Blix}

Department of Sociology, Stockholm University, S-106 91 Stockholm, Sweden

E-mail: stina.bergmanblix@sociology.su.se

\begin{abstract}
We examine the distinctions between 'playing' and 'playing at' and between deep and surface acting made by Goffman and Hochschild, using examples from stage-rehearsals. This reveals how stage actors switch between these modes and employ various manifestations, rather than using either of them exclusively. The findings are thought to have conceptual implications beyond the particular case of stage acting. One tentative conclusion is that the difference between an actor rehearsing an emotion-laden situation and experiencing a similar situation in real life lies in how the situation is confronted and handled rather than in the actual emotions.
\end{abstract}

Keywords: stage actors; emotional labour; deep acting; profession; theatre; Goffman; Hochschild.

Reference to this paper should be made as follows: Bergman Blix, S. (2007) 'Stage actors and emotions at work', Int. J. Work Organisation and Emotion, Vol. 2, No. 2, pp.161-172.

Biographical notes: Stina Bergman Blix is a Doctoral Student at the Department of Sociology, Stockholm University, Sweden. Her thesis deals with various aspects of stage actors' professional competence, particularly their work with emotions, two examples being their emotional reactions during the early phase of rehearsing a play and their moving in and out of emotions throughout the work with a production.

\section{Introduction}

In one sense we all play roles. At home we play the part of mothers, fathers, sisters, brothers, and neighbours. Then we go to work and play lawyers, nurses, farmers, or whatever our profession is. For most of us, our roles are routinised and partly internalised, and thus, well integrated into both our private and professional life. A stage actor, in contrast, has to learn new roles constantly, and her or his professional knowledge is not restricted to the roles she/he plays, but rather concerns role-playing as such, i.e., how to make new roles come to life. Stage actors live the part of a role using their body, voice, imagination and feelings. They professionalise the acting we all do in everyday life; they control an ability we all have to some degree, but perhaps are not so aware of. Therefore, studying stage actors can teach us something about everyday role-playing, as argued by Goffman $(1959,1961 \mathrm{~b}, 1974)$ and, regarding the emotions, as developed further by Hochschild $(1979,1983)$. Their analyses, however, were based 
on stage acting in theory rather than as a lived experience and were, therefore, as we shall see, too simplified in their treatment of how stage actors actually work with emotions.

You may argue that mothers and fathers are not playing roles: They are mothers and fathers. However, as discussed below, playing a role does not necessarily entail a make-believe performance; it merely denotes adherence to the attitudes and behaviours associated with being, e.g., a mother or a father. As Hochschild argues, both our professional and our private roles require that we manage our emotions in order to function in various social situations and stage actors also do emotion work (or following Hochschild's definition, emotional labour) in portraying a role, although in a protracted and deliberate manner. As part of their professional competence, they gradually unfold and lay bare the emotions of another, fictive person and, as part of this process, probe into their own emotions.

This paper draws on material from a study of six participants (Blix, 2004) and from observations of rehearsals, several informal talks and 19 interviews with 12 stage actors during the two-month rehearsal of a Swedish theatre production and the first weeks of performance. This particular production was selected so as to obtain as rich a variety of acting experience as possible. The chosen project included actors of both sexes, with a great range of experiences, diverse employment conditions and different ethnic backgrounds. Field-notes were made continuously during the rehearsals concerning several aspects of the stage actors' work and were then used to formulate specific questions that were posed to the actors throughout the rehearsal phase and at the beginning of the performance phase. Prior to the rehearsals, two hour-long interviews with a very experienced actor were conducted and analysed to develop an understanding of what to look for. All interviews were listened to repeatedly, and conclusions were tested using respondent validation with several of the participants. We had insider knowledge: the author's earlier work as an assistant director both made the field available and made it easier to interpret the meaning of the situations within the frame of reference of the stage acting profession (Schütz, 1944). The quotations presented here have been slightly modified to facilitate understanding.

Stage actors are emotional labourers par excellence. The purpose of the present paper is twofold: to analyse how stage actors work with emotions during the rehearsals of a play and to investigate how this emotion work relates to their private emotions. It is suggested that the difference lies in how emotions are confronted and handled rather than in the actual emotions. First, I present a summary of Goffman's description of stage actors, and then I move on to Hochschild and her critique of Goffman. I provide several examples showing that both Goffman and Hochschild oversimplify the role-playing performed by stage actors. Finally, a more complex view on stage actors' work with emotions is outlined.

\section{Goffman on stage acting}

The present reading of Erving Goffman focuses solely on his descriptions of stage actors and stage acting. Although he uses the theatre as a metaphor in analysing everyday behaviour, and not for describing theatre per se, the analysis becomes more efficient the more it coincides with the actual phenomenon, in this case, stage acting. 
Goffman defines a role as "the typical response of individuals in a particular position" (Goffman, 1961b, p.82). Goffman based many of his descriptions of roles and role-playing on the theatrical stage and stage acting. Although Goffman uses theatre binoculars to picture the world and the situations we play our roles in, his view on the role-playing performed by stage actors is profoundly different from his view on the role-playing we all do in everyday life. The embracing and playing of a role in ordinary life is used, by Goffman, to describe how we relate to situations and encounters and does not imply a distance to the 'actual self' that is associated with the common meaning of 'playing'. In order to embrace a role in ordinary life, it is necessary to express an attachment to it, to demonstrate a capacity to perform it and to engage actively in the activity that is expected by the role. To embrace a role is to fully immerse oneself in the 'situated self' that acts in the situation: "To embrace a role is to be embraced by it" (Goffman, 1961b, p.94).

On the other hand, 'playing at' contains a distance from the self and is, in his definition,

"... when children, stage actors, and other cutups mimic a role for the avowed purpose of make-believe; here, surely, doing is not being." (Goffman, 1961b, p.88)

According to Goffman, the difference between a professional actor and a child is that actors perform their roles with more stamina and perfection. Although 'playing at' involves a distance to the role, it can still be performed with feeling (Goffman, 1961b, p.117). Because the stage actor does not have to take responsibility for the actions of her or his character, which are performed in a make-believe world, and because the audience knows it is make-believe, the actor need not show a distance to the role, but can actually embrace it, making 'playing at' different from other forms of 'secondary adjustments' (Goffman, 1961a) and 'role distance' (Goffman, 1961b), which Goffman points out elsewhere. According to Goffman, stage actors instead become over-involved with the feelings associated with the character, because they can perform them uninhibitedly without the risk of side effects that may occur in daily life, such as feeling embarrassed about showing too much enthusiasm in a situation that calls for self-restraint or getting fired for yelling at the boss.

Goffman metaphorically uses the 'frames' of the theatre to describe our everyday encounters. He uses stage acting to elucidate how important the situation and the frames are for our interpretation of, and acting in, the situation (Goffman, 1974). The interpretation is then limited to how our encounters are structured and loses sight of the subjects in the encounter. Goffman shows how keying and fabrication are done on stage with the use of different framings and concludes that there are many similarities with everyday life. When people stalk, delude or deceive each other, they actually work with the situational frames to their advantage.

An immediate limitation of merely focusing on the situation and framing is that the acting subject almost becomes a determinate marionette. Goffman's emphasis on the situation is evident in the often-cited "Not then, men and their moments. Rather moments and their men" (Goffman, 1967, p.3), a shift in focus that can be useful, but that also leads to a loss of nuances when applied to the experience of emotions. If we study great stage actors or persons considered to be distinguished members of a particular profession, these persons often interpret their roles freely, allowing themselves to be unique. Thus, displaying good self-confidence, not caring too much about the standard 
requirements of a role and allowing one's unique qualities a great deal of scope could be a way to succeed in role-playing. Obviously, some people are more likely than others to succeed in that endeavour, for instance, people with the right cultural capital (Bourdieu, 1980) or the right sex or ethnic background. The point is that there must be an inward resonance if the role is to be convincing. If this resonance is complete, then much of the role's standard requirements can be disregarded and the enacting of the role can still be credible or even constitute a role model.

To sum up, Goffman's view on stage acting clearly has to be modified so that it can encompass emotions in a more multifaceted way. Dismissing acting as 'playing at' as he does constitutes simplification of a more complex matter. Thus, in order to analyse role-playing, both in everyday life and in professional stage acting, where the character is built on a continuous dialogue between the role, the director, co-workers and the actor's own body and experiences, a subjective approach is necessary that addresses the emotional aspects that are concealed when only the structure is in view.

\section{Hochschild on surface- and deep-acting}

Goffman's work contains many vivid descriptions of outer expressions and people disguising their selves. Thus, it is not surprising that he has been accused of not differentiating between the acting that implies management of outer expressions and the acting that implies management of emotions (Hochschild, 1979).

In her critique of Goffman, Hochschild $(1979,1983)$ conducts a comprehensive analysis of stage acting - particularly in an appendix to The Managed Heart. She bases her description of stage actors on a work by Stanislavski (1936), the most well-known acting pedagogue in Western theatre. Hochschild refers to two different acting techniques - the English technique and the Stanislavski technique. The English technique represents 'surface acting', in which the actor controls his or her gestures and facial expressions in detail to convince the audience that she or he is a certain character. The Stanislavski technique, on the other hand, represents 'deep-acting', in which the actor uses her or his own emotions in portraying a role, thus enacting the role in a deeper, more personal way (Hochschild, 1979, p.558). These different approaches, according to Hochschild, reflect the way people work with their emotional appearance in other professions as well.

In Goffman's work, people do indeed have emotions and, as described above, stage acting does involve emotional expression, but the emotions just seem to be there, without any effort on the part of the people expressing them. Hochschild, on the other hand, focuses on how people work with emotions in order to express them to the right extent and when expected. She, thus, distinguishes between 'emotion work', which refers to our management of emotions in private life, for example trying to express happiness at a party, and 'emotional labour', which refers to the same type of work in professional life, for example, trying to be friendly to customers or empathic towards patients. Ashforth and Humphrey have argued that surface acting does not imply lack of emotion, only that the displayed emotion may be different from the felt emotion (Ashforth and Humphrey, 1993, p.92). However, although these categories are empirically as well as conceptually well-founded, I will argue that, in acting schools as well as in acting practice, there is no clear-cut distinction between surface and deep acting, or between 'playing at' and 'playing', as conceptualised by Hochschild and Goffman, respectively. 
Instead, stage actors switch between and employ various manifestations of these modes depending on the situation and their individual preference.

\section{Stage acting}

Working with a theatre production often starts with the play, the manuscript in which all the roles and the context they act in, the plot, are described. The role is the starting point for the actor to work with. Together with the director and the co-actors, the actor moulds the character. The character, in this sense, is a combination of role, the director's input, the actor's imagination and the co-actors' input. (Ordinary everyday life does not have these seven features writ quite so explicitly.) Here, I will focus on the rehearsing process, but of course the relation to the audience is also of significance in the performance.

Emotional labour in various professions requires face-to-face meetings in which the working person has to respond immediately, and thereby more or less intuitively, to the emotional state of others. In performing on stage, the actor too has to respond immediately to both co-actors and to the audience. In the rehearsing process, on the other hand, the stage actor encounters a prolonged meeting with a role figure, in which she/he functions as both the giver and the receiver of emotions in order to bring the role figure to life. Therefore, the focus here is on the rehearsing process.

A previous study on stage acting (Blix, 2004) generated five dimensions of the actors' professional competence:

- mastery of technical skills, such as being able to control one's voice and body

- daring to approach each new role with an open mind

- $\quad$ being able to work effectively with co-actors in an ensemble

- $\quad$ having the capacity for a high degree of empathy

- $\quad$ being able to keep one's professional and private life separate.

Most of these dimensions are relevant to the emotional aspects of an actor's work. In order to describe the conditions of the rehearsing process, whether the actor commences by way of deep or surface acting, the second dimension will be explained and then use of the body and voice and the separation between professional and private life will be elaborated on in more detail.

\subsection{Daring to approach each new role with an open mind}

The definition of 'playing at' employed by Goffman is used to elucidate how emotions can be expressed without risk for the actor involved, making the feelings purer or less complicated to handle. This is fair when referring to performances in which the emotions are rehearsed and set (Konijn, 2000), but must be qualified when analysing rehearsals. Goffman refers to a 'backstage' in which actors relax and shed the role character (Goffman, 1959, p.112). The stage actor indeed has to 'drop his front' when rehearsing a performance, but she/he is still being observed when working 'backstage'. According to Goffman's definition, the rehearsing of a role can be considered 'frontstage', because the actor is being assessed by co-workers and the director, but, as we shall see, it differs from the actual performance in several ways. In interviews with stage actors, the significance 
of daring to have an open mind - which entails encountering personal emotions, such as early experiences of emotional significance when studying a new role together with the director and with co-actors - was often described as more problematic and frightening than the actual performances (Blix, 2004). Thus, in analysing stage actors' role-playing, it is important to separate the rehearsing process and the performances.

Portraying emotions is a vital part of the stage actor's work. In a profession where emotions are tools, the working process also comes to be surrounded by emotions, generated from the predicament of working with one's own body and feelings. As can be seen in this quote from an interview with a stage actor, fear and courage are often-mentioned feelings in the rehearsing process.

"Every time I start to rehearse something new, a lot of old insecurities come to the surface."

"Even though I agree that it's good to just dive in and take risks, this is exactly what I find scary and have a hard time doing. So, it's a mix of not being too hard on myself and at the same time continuing to challenge myself. Not to start by saying "No, I can't do that, not on the first day", but to find a way to try, and not be too hard on myself if I do not succeed."

Using a quote from Goffman in which he refers to an actor's account of her fears of playing an explicit lovemaking scene, a contrasting analysis will be made (from an interview in The New York Times, December 29, 1968):

"I was very frightened. You can't do a scene like that - at least I can't - without trust. Unless you are drunk - and I wasn't drunk. But over a period of two or three days, you don't stay at the same level of trust. I worried horribly. It was a difficult period. Difficult for me and difficult for Coral (Brown). I think that there's very little that's more vulnerable than being an actor. You're a writer, but it's your book. If you're a painter, it's your painting. But if you're an actor, it's you - it's your face, your skin, your body. Well, they can have all that. They can take your body and your face. But nobody can invade your thoughts. And what worried me, what terrified me, was the fear that this was the moment that I was not going to be mine anymore..." (Goffman, 1974, p.279)

Goffman interprets the actor's fear in terms of frame-breaking. At that time, the movie in question was breaking the limits of the cinematic frames concerning exposed sexuality. This frame-breaking can have real consequences for the actor outside the make-believe world. Goffman stops at that, but the analysis can be taken further.

When the stage actor rehearses for a play, she or he must use her or his own body and search for her or his own feelings to make the character come to life on stage. The actor must be open to impulses in order to play a character without adjusting to preconceived ideas about how certain characters behave. Initially, she or he has to dare to make inadequate interpretations while in search of 'true' ones. When it comes to sexuality, the norms for behaviour may be very stereotyped. Departing from such norms can, no doubt, be terrifying. Trying to create a love scene, in character, but using one's own experiences in choosing ways of touching and responding to the other person's touches, undoubtedly takes courage and trust. When the role is enacted in front of an audience, the characters in the performance are rather settled and one's vulnerability is not as evident as in rehearsals. In movies, the scene only has to work once, so the rehearsals do not settle the character like in the theatre. Creation of the scene can thereby be likened to the rehearsing process in the theatre as concerns the actor's vulnerability. Thus, the fear 
expressed by the actor above, is associated with frame breaking in a more profound way than that expressed by Goffman.

During the project rehearsals, I followed an actor who once came to rehearsals crying for private reasons. She then went straight in and performed a scene in which she yells at a whole group of people. She had had difficulties with that scene earlier, but told me afterwards that her sad mood helped her get through her ordinary inhibitions about being aggressive. A private emotion thus shaped her professional emotion work. Emotions from a character can also spill over to the actor's private life:

"I did a role last autumn that was absolutely wonderful to play, but I couldn't control it anymore. It controlled me totally. It took over my life. I couldn't sleep. I dreamt about it, solutions and such. Lost weight. But it was wonderful to play!"

This example is rather extreme and not something that happens to every actor every time, but it nevertheless illustrates the effect that a fictional situation can have on an actor. Referring back to Goffman's point about stage acting being make believe, enabling the actor to embrace the role more, this could be an illustration of embracing, in some ways, having dissolved the make believe. Not that the actor actually believes that she or he is the character, but that there can be extreme emotional consequences outside of work resulting from working with a character. (Hochschild reported a milder version in some crews' inability to stop smiling at the end of a shift.) The supposed lack of emotional consequences for the stage actor, associated with what Goffman calls 'playing at' as opposed to 'playing', becomes more complex when analysed in detail.

As we shall see, similar complexity is also found when looking more closely at deep - and surface-acting, both of which accompany the actor's attempts to 'get in touch' with their character's emotions. The next section will discuss how actors instigate emotions when working with a character.

\subsection{Expressing emotion: using one's body and voice}

Studies of emotional labour investigate the management of emotions, often referring to the suppression of emotions. In acting work, the actor aims at expressing emotions, and the use of empathy to identify with a character, and methods of triggering emotions are essential. (Other emotions are not so much suppressed as 'parked out of the way'.) How does the actor go about getting in touch with her or his emotions?

There is a plethora of methods within the whole range, everything from sedentary contemplation to extreme physical activity. Actors can use a method wholeheartedly, but in most cases they combine a set of tools that has worked previously. A few examples will suffice to show that the distinction between surface and deep acting is not as sharp as it might seem. The technical skills - being able to control one's body and voice - can be seen as tools, not only for reaching out to a large audience, but also, as can be seen from the following quote from an interview with a stage actor, as a means of reaching inside the text and finding emotional cores within oneself that are related to the role figure.

"Sometimes it can be useful to start from the outside ... it is possible to release a lot of feelings and desires, and the lines can start to flow if you adopt a special body pattern." 
The display of surface acting through gestures can be used as a method to instigate deeply felt emotions. In acting classes, for example, physical activities are frequently used to trigger emotions. One example is to 'jump like a frog' for a very long time. After jumping to exhaustion, the actor can go into a scene without the defences she or he would otherwise build up due to social conventions. The emotions are set free as a result of physical activity. Another example of a similar kind is the laughing classes that have become popular during the past decade. The idea is that the participants start to laugh in a 'fake' mechanical way and that, after a while, the artificial laughter turns into genuine laughter. The assumption that the physical activity associated with a certain emotion actually conjures up the emotion is often described in actor's handbooks. "Kick a wall to become angry", "move fast to become nervous", etc., are ways to prepare for an upcoming scene that presupposes a certain emotional state. Using physical and mechanical activities to open up for emotions seems to lead to two different scenarios. The emotion can emerge from the activity itself with no empathic process involved. This fits with the view that emotions can be understood in terms of scripts (Saarni, 2000) containing physiological, motoric (gestures and facial expressions), as well as cognitive components. If part of the script is activated, the others will follow. Costume can often be such an instigator. An actor once told me that, before he went up on stage, he pulled his pants up a bit too high, which helped him get into character. Another use of physical activity is to clear the way for an openness that facilitates the initiation of an empathic process. Inhibitions in expressing feelings have physical correlates, constituting a muscular armour (Reich, 1950). If these are softened by physical activity, relaxed by, for example, pharmaceuticals or massage, the probability that the emotions will be released increases. The above-mentioned story of the sad actor performing a wonderful anger scene is an example of that scenario.

Just as physical gestures can bring out emotions, the use of voice and speech can have the same effect. Work with placing consonants and vowels correctly, using the body as a soundboard, is necessary if the audience is to hear the actor from the stage, but it can also affect the actor emotionally (Ekmanner, 1998). Ekmanner, a well-known Swedish actress, describes this vocal process when the text is spoken:

"as a resistance starts to let go, I can open up my boundaries between inside and outside and between feeling and intellect." (Ekmanner, 1998, p.10, my translation)

The question of eliciting the emotions 'inside' is however not exactly the same as the question of privacy.

\subsection{Being able to keep one's professional and private life separate}

Stage actors work on the boundary between a private and a professional role. They use themselves and their bodies to play a character, and sometimes the line between private and professional life can get blurred. One example of this is falling in love privately with the co-actor on stage, something often described as a beginner's problem by the actors I interviewed. But, as can be seen from the following quote from an interview with a stage actor, even the experience of falling in love can be described in more nuanced terms than as simply either 'private' or 'professional': 


\begin{abstract}
"When I know I'm going to play with someone, especially when there's going to be an attraction between us, I notice that I look at that person differently. It is as if I open up to feeling an attraction. And one is so skilled ..., of course it is possible to fall in love for real, but most often it's almost like a crush, but I know that it's not for real. It has to do with the situation and maybe, not consciously, but it's almost as if one creates it."
\end{abstract}

The quote suggests two things: First, the actor describes being aware of a very private feeling and lays it out on the table, as it were, even talking to the co-actor in question about it, thereby turning something private into an ordinary, work-related human predicament. Second, the actor differentiates between feelings that are primarily elicited either by the situation or by her or his personal prerequisites.

One can learn by experience to shield one's personal integrity from other people, but it seems to be harder to protect oneself from oneself. Arousing feelings of sadness or anger on the stage night after night can be very demanding. There is no doubting that this is work. The actors I interviewed described two different effects of that predicament. They either described the emotional release as liberating or talked about it in terms of 'draining their reserves', causing them to need more sleep or to drink more alcohol (Blix, 2004, p.67). Another issue that is relevant when examining role-playing is how the building of a character relates to stereotypes of such characters, and how these fictional characters relate to felt emotions.

\title{
4.4 Can acted emotions be genuine?
}

Goffman interprets stage acting using an outside perspective. In defining the role's relationship to the actor playing it, he assumes that the role and the actor are two separate entities (in the quote below Goffman uses 'role' to describe the text, and 'creature' to describe the playing of the role on stage):
"On the stage a whole 'natural' person is projected, a full identity whatever the special role requirements of a particular scene. As such, the performer will have to enact appropriate creature releases, for obviously the typical discrepancies between performer and role are ones the actor must put into his part if he is to perform a seemingly genuine, fully rounded person." (Goffman, 1974, p.206)

I would argue that, from the actor's perspective, another interpretation is necessary and more fitting. The character is moulded from the actor's own body, voice and experiences - there is no such thing as an ideal role-type that the actor should mimic. One actor's Ophelia can never be the same as another actor's Ophelia, and neither of them is more accurate than the other - the interpretations are different and probably attract different audiences. As can be seen in this quote from an interview with a stage actor, this does not contradict the fact that a role like Ophelia's contains a vast number of conventions that the actor must relate to:

"If one takes the original example, Hamlet, it contains a vast number of conventions based on the work I've done and seen, that I've experienced and so on. And, to break with that, or to let oneself be surprised by something else, it is essential to go past the conventions. It is impossible not to use the conventions; one should use them. But one has to be open to points at which one has a realistic opportunity to surprise oneself and others." 
If we, instead, assume that the actor interprets the role subjectively and not based on a predefined stereotype, new insights into how we enact roles can be made. Both in acting and in reading novels, we use our own experiences to bring fiction to life. When we read a novel, the author gives us more information for our fantasy than the actor has access to through reading stage scripts. When we watch a movie or a theatre production, the characters are more vividly interpreted by the actors than they are in a novel, where our fantasy must contribute to the visualisation. The actors create that visualisation, in collaboration with the director and other co-workers, and thereby limit the range of our frames of interpretation, drawing our focus to their selected reading of the script. Contrary to Goffman's view, there are no ideal-type models that actors or readers of a script mimic; the interpretation of a play is different for every individual spectator, depending on her/his personal biography and current state of mind. However, our subjective interpretations overlap with those generated by other spectators or readers, allowing us to share our experience of the novel, play or movie with one another.

A common argument referring to the supposed lack of genuineness of a stage actor's work with a role, and the emotion work it requires, is that it does not happen in reality. If an emotion is not preceded by an actual event, it is not as true as one arising from a real situation. The actor has not really lost her child, this has just happened in the manuscript. According to this definition, the sadness or anger the actor shows can not be genuine when the event is fictional. This argument, however, disregards all the affects that reading fiction or seeing a movie or a play might arouse in a spectator; the emotions generated by such experiences are not preceded by actual events, but by fiction brought to life by one's imagination. The well-known phenomenon of someone's life taking a new direction in response to having read a novel or the idea that violent movies generate youth criminality (Savage, 2004) are examples in which fiction seems to affect people's lives in profound ways. (Indeed affects are all too easily underestimated and trivialised.) On the other hand, in everyday life we are not perfectly attuned to specific events all the time. We always carry our history with us (our back stories). An event and the corresponding emotion are seldom linearly related in time. For someone whose husband died in the autumn, seeing a red leaf on the lawn might generate feelings of loss years afterwards. The original cause of the feelings may no longer be vivid. Many of our characteristic strategies and feelings are nevertheless historic, emanating from childhood, particularly. Even if the events that originally triggered the feelings have long since been forgotten, the emotional sensitivity to certain situations remains.

The difference between feigning and not feigning an emotional expression is, thus, not absolute or given; there are probably degrees of closeness to the emotion at hand and degrees of distance to the events through which we learned the feeling. Even from moment to moment within a play, actors can not uphold the same level of empathic understanding for the whole duration, rather, they strive to make 'the emotional points' spread to and colour the passages that are not felt as genuinely. Sometimes, actors can lose their character due to technique problems, such as when spotlights are pointed at the wrong actor, or when audiences are disturbing. One actor described such an occasion of unpleasant inauthenticity: 
"Everything becomes unmasked. I drop the fiction. It becomes naked and ugly and artificial, what am I doing here? There are a lot of things that can run through your head when the fiction falls out."

Another actor describes a scenario in which the actor's awareness is split into two parts, one that takes part in the fiction on stage, while the other dwells on trivial matters such as dinner plans. One reason for the varying degrees of closeness may relate to the fact that actors have to attend to tasks such as placing props, handling the stage design as if it were real or waiting for cues that are outside the character. At the same time, she or he acts 'as if' the situation was real and uses her/his private body and emotions in playing a role (Stanislavski, 1936). For instance, when an actor moves a prop from one side of the stage to another in order to prepare for another scene, she/he must do this 'in character'. If she or he were to treat the prop as a prop, the audience's attention would immediately turn away from the play to the actual prop. These outer conditions can be more or less in accordance with the character and often have to be a compromise between what the character would do and what the actor has to do, so that the audience will understand and remain absorbed by the play.

\section{Conclusions}

I have given some examples which establish a more complex view on the relationship between 'playing' and 'playing at' and between deep- and surface-acting, showing how the stage actor switches between, and employs, various manifestations of these modes rather than using any of them exclusively. Stage actors often refer to the rehearsing process as proceeding either from 'inside out', starting with one's imagination and from there generating the external expressions of the character, or from 'outside in', starting with external expressions that find resonance in one's imagination. At some moments in the play, neither of the processes is satisfactory and the performance must move on with limited inner resonance. These moments, however, can be preceded or followed by acting that has an inward resonance. Using Hochschild's terms, the actors thus reach deep acting by way of surface acting; they engage in deep acting wholeheartedly or they colour their deep acting with surface expressions. To complicate the matter further, an individual actor's work with deep- and surface-acting can vary both across and within productions. Even though stage actors in the Stanislavski tradition, in some sense, internalise the role, that is, perform deep-acting, they are at the same time aware that it is just a role.

A more nuanced description of surface and deep-acting and, tentatively, of 'playing' and 'playing at', ought, nevertheless, to have conceptual implications beyond the specific case of stage acting. The use of surface-acting to reach deep-acting, for instance, can be expected to have much wider applicability in every day life, and this is probably also true of the reverse strategy, i.e., moving from deep to surface-acting, although this remains to be investigated more closely.

The outer-inner dimension seems to be common to acting, to other forms of emotional labour and to ordinary being in the default state. In order to work effectively when using one's body and emotions as tools, it seems vital to be able to regard the feelings generated by work as work feelings, elicited by the work situation rather than by personal prerequisites and to accept and express the feelings generated by the work and not try to pretend that they do not exist. For example, situations on the stage can sometimes be embarrassing for the actors involved. In such cases, giving full expression 
to that embarrassment in the rehearsing process is necessary to avoid it in the performance (and why not exorcise any such feelings in a similar way when rehearsing other types of emotional labouring roles?). The larger, if tentative, conclusion of this research is that the difference between an actor rehearsing an emotion-laden situation and experiencing a similar real life situation is a matter of degree rather than quality. The difference lies in how the situation is confronted and handled, assisted by the actor's range of professional techniques, rather than in the actual emotions.

The issues presented here require further elaboration and must be put into a wider frame of reference in order to elucidate the relationships between the various components of the stage actor's work. Such an analysis might result in a model for how emotions are instigated and how motives and emotional states are utilised in other professions - with their different and specific techniques - as well. However, I trust that the reader will think twice the next time they see emotional labourers at work, such as police officers or cabin crew, referred to as actors. In a way they are, but in other important ways they are not quite the actors we have described here. The differences, however, are in degree.

\section{References}

Ashforth, B.E. and Humphrey, R.H. (1993) 'Emotional labor in service roles: the influence of identity', Academy of Management Review, Vol. 18, No. 1, pp.88-115.

Blix, S. (2004) 'Skådespelarens yrkeskunnande: en fenomenologisk studie, a phenomenological study of the competence of professional stage actors', Sociologisk Forskning, Vol. 1, pp.55-74.

Bourdieu, P. (1980) The Logic of Practice, Stanford University Press, Stanford.

Ekmanner, A. (1998) 'Förvandlas - om skådespeleri', in Birnbaum, D. and Zern, L. (Eds.): Försök Om Teater, Stockholm, Bonnier, pp.7-36.

Goffman, E. (1959) The Presentation of Self in Everyday Life, Doubleday Anchor Books, New York.

Goffman, E. (1961a) Asylums - Essays on the Social Situation of Mental Patients and other Inmates, Penguin Books Ltd., Harmondsworth.

Goffman, E. (1961b) Encounters - Two Studies in the Sociology of Interaction, Penguin University Books, Harmondsworth.

Goffman, E. (1967) Interaction Ritual - Essays on Face-to-Face Behavior, Pantheon Books, New York.

Goffman, E. (1974) Frame Analysis - An Essay on the Organization of Experience, Northeastern University Press, Boston.

Hochschild, A. (1979) 'Emotion work, feeling rules and social structure', The American Journal of Sociology, Vol. 85, November, pp.551-575.

Hochschild, A. (1983) The Managed Heart: Commercialization of Human Feeling, University of California Press, Berkley.

Konijn, E.A. (2000) Acting Emotions - Shaping Emotions on Stage, Amsterdam University Press, Amsterdam.

Reich, W. (1950) Character Analysis, 3rd ed., Vision Press, London

Saarni, C. (2000) 'The social context of emotional development', in Lewis, M. and Haviland-Jones, J.M. (Eds.): Handbook of Emotions, 2nd ed., The Guilford Press, New York, pp.306-322.

Savage, J. (2004) 'Does viewing violent media really cause criminal violence? A methodological review', Aggression and Violent Behavior, Vol. 10, No. 1, pp.99-128.

Schütz, A. (1944) Collected Papers 1, The Problem of Social Reality, Nijhoff, The Hague.

Stanislavski, C. (1936) An Actor Prepares, Theatre Arts Books, New York. 